\title{
Erratum to: Reliability of the imaging software in the preoperative planning of the open-wedge high tibial osteotomy
}

\author{
Yong Seuk Lee - Min Kyu Kim • Hae Won Byun • \\ Sang Bum Kim • Jin Goo Kim
}

Published online: 30 November 2013

(C) Springer-Verlag Berlin Heidelberg 2013

\section{Erratum to: Knee Surg Sports Traumatol Arthrosc}

DOI 10.1007/s00167-013-2700-z

Unfortunately, one of the author's names Min Gyu Kim was published incorrectly with spell error in the original publication. The actual name should be read as Min Kyu Kim. The corrected author group is given below.

Young Seuk Lee, Min Kyu Kim, Hae Won Byun, Sang Bum Kim, Jin Goo Kim.

The online version of the original article can be found under doi:10.1007/s00167-013-2700-z.

\section{Y. S. Lee}

Department of Orthopedic Surgery, Gachon University Gil

Hospital, Inchon, Korea

e-mail: smcos1@hanmail.net

M. K. Kim · S. B. Kim · J. G. Kim ( $₫)$

Department of Orthopedic Surgery, Seoul Paik Hospital, Inje

University, Jeo Dong 2Ga, Gung Gu, Seoul, Korea

e-mail: boram107@hanmail.net

H. W. Byun

School of Information Technology, Sungshin Women's

University, Seoul, Korea 